Acta Hispanica (2020) Supplementum II: 687-698

\title{
TRATAMIENTO INFORMATIVO DE AMÉRICA LATINA EN LA PRENSA MARROQUÍ
}

\author{
AbDelHaK HiRI \\ Instituto Superior Internacional de Turismo de Tánger
}

Resumen: El presente trabajo parte de un objeto de estudio muy concreto: conocer el tratamiento comunicativo ofrecido por la prensa escrita marroquí de América Latina. Para realizar este trabajo, nos basaremos principalmente sobre las herramientas del análisis de contenido, a través del estudio de alrededor de 2752 textos periodísticos que conforman el corpus. El estudio se centra en los siete periódicos de gran trascendencia histórica en Marruecos: La Mañana del Sábara y del Magreb, Le Matin, Al-Alam, Al-Ittibad Al-Ichtiraki, L'Économiste, Anoual, Al-Massae, durante el periodo de enero de 1990 a diciembre de 2015.

Palabras clave: imagen, América Latina, prensa marroquí, análisis de contenido.

\begin{abstract}
This article offers an analysis on how Latin America was represented in the Moroccan press. To this end, we have analysed a total of 2752 newspaper articles, using content analysis tools. The study focuses on the seven most influential Moroccan newspapers: Le Matin, Le Matin du Sahara et du Magreb, Al-Ittibad Al-Icbtiraki, Al-Alam, L'Économiste, Al Massae and Anoual. The articles extend over a period of 25 years, from January 1990 to December 2015.
\end{abstract}

Keywords: Image, Latin America, Moroccan Press, Content Analysis.

\section{Introducción}

Los contenidos del presente artículo describen y analizan la totalidad de los resultados obtenidos de una investigación doctoral comparativa y específica sobre las publicaciones informativas de América Latina en la prensa marroquí. Nuestro propósito, pues, es poner de manifiesto cómo está informado el lector marroquí de América Latina y los latinoamericanos a través de la prensa escrita marroquí. Creemos que este trabajo resulta muy significativo para la búsqueda de las vías de comprensión y de comunicación intercultural en las relaciones de América Latina y Marruecos, que a pesar de la distancia geográfica, están ligados, desde tiempos inmemoriales, por vínculos histórico-culturales, problemáticas de desarrollo y desafíos similares y en las últimas décadas han construido relaciones amistosas y fructíferas. Nuestro interés por este tema procede de la idea de que los medios de comunicación de prensa ejercen una notable influencia sobre la opinión pública. En este sentido, cabe citar la opinión de Cándido Monzón, quien establece un tipo de relación causa-efecto entre los medios de comunicación y opinión pública: 
Tratamiento informativo de América Latina en la prensa marroquí

La opinión pública ha encontrado siempre en los medios de comunicación su mejor medio de expresión [...] Las opiniones son de los públicos, pero su publicidad está en los medios, de aquí que siga oyéndose en la actualidad que la opinión pública es lo que dicen los medios de comunicación (Ramírez, 2005: 177).

Atendiendo a la precisión anterior, podemos inducir que los medios se constituyen como mediadores que se encargan de transmitir y marcar las opiniones. La mayor parte de nuestro conocimiento social y político, así como nuestras creencias sobre el mundo emanan de las decenas de informaciones que leemos o escuchamos a diario. Con el propósito de conocer cómo queda representada América Latina en la prensa marroquí, más concretamente cómo los sietes periódicos marroquíes dieron cobertura mediática al subcontinente latinoamericano, hemos estimado conveniente optar por el análisis de contenido. Según el académico Laurence Bardin, el análisis de contenido es:

El conjunto de técnicas de análisis de las comunicaciones tendientes a obtener indicadores (cuantitativos o no), por procedimientos sistemáticos y objetivos de descripción del contenido de los mensajes, permitiendo la inferencia de conocimientos relativos a las condiciones de producción/recepción (contexto social) de éstos (Bardin, 1996: 32).

De esta manera, podemos sintetizar que el análisis de contenido es una técnica que permite explicar y sistematizar el contenido de los mensajes comunicativos. En esta investigación delimitamos el área de estudio en los siguientes siete periódicos marroquíes: Le Matin, La Mañana del Sáhara y del Magreb, Al-Ittihad Al-Ichtiraki, Al-Alam, L'Économiste, Al Massae y Anoual. Lo que justifica la elección de estos medios es que representan a los principales grupos periodísticos nacionales de Marruecos. Son periódicos de gran presencia en todo el territorio nacional con una gran tradición histórica, ampliamente conocidos y con posicionamientos editoriales diferentes.

Para delimitar de forma abarcable y a la vez científica, se ha establecido un periodo de análisis de 25 años de estudio hemerográfico, desde el 1 de enero de 1990 hasta el 30 de diciembre de 2015. La razón de la elección de este marco temporal se debe, principalmente, al principal interés nuestro por estudiar una muestra muy amplia y representativa que arrojaría una evidencia empírica sobre la cobertura informativa de América Latina en la prensa marroquí. En líneas generales, la metodología utilizada se enmarca en tres etapas: primero, una selección de la muestra (recogida de información); segundo, la elaboración del corpus, y tercero, el análisis de los resultados y las conclusiones principales. 
Abdelhak Hiri

\section{Descripción de los resultados obtenidos}

Los contenidos del presente capítulo describen y analizan la totalidad de los resultados obtenidos del corpus estudiado a lo largo de veinticinco años de seguimiento. De hecho, este estudio sintetiza los principales resultados de una investigación comparativa y específica sobre las publicaciones informativas de América Latina en los siete periódicos seleccionados. Con este trabajo pretendemos analizar los distintos aspectos formales y cuantitativos de la presencia de América Latina en la prensa escrita marroquí.

\subsection{Distribución de las piezas seleccionadas por diario (1990-2015)}

En este primer capítulo se expone la producción editorial que los siete periódicos marroquíes seleccionados han publicado sobre el subcontinente latinoamericano. En el gráfico se visualiza la distribución sectorial basada en los porcentajes de noticias publicadas por cada diario:

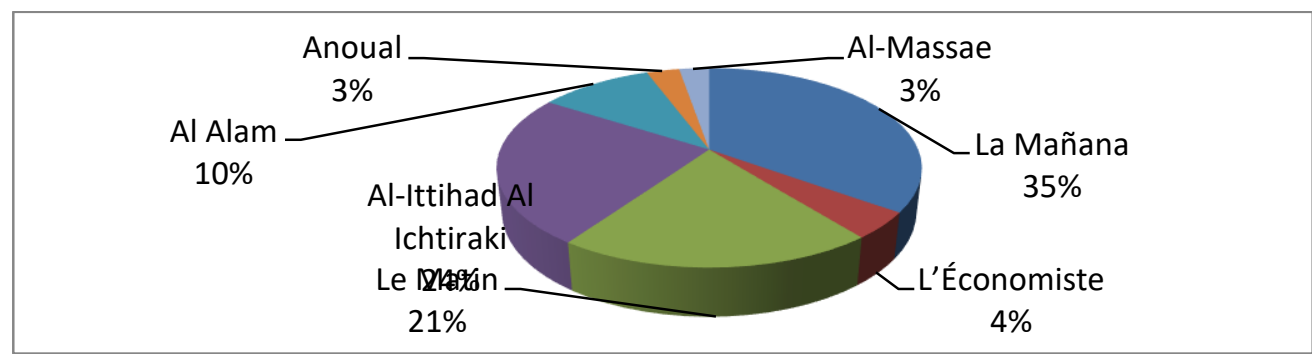

Gráfico No.1: Volumen informativo por diario 1990-2015

(Fuente: elaboración propia a través del corpus recopilado)

Observando los datos arriba expuestos, se puede apreciar que el corpus documental derivado de la consulta hemerográfica de los siete periódicos estudiados abarca un total de 2752 textos periodísticos. Una primera lectura de estos datos permite observar que la cobertura informativa de América Latina en el conjunto de las publicaciones de las siete cabeceras estudiadas es nítidamente deficiente y exigua. Esto implica que los lectores marroquíes recibieron muy poca información del subcontinente latinoamericano. Además, como podemos observar a primera vista en el gráfico, se nota un marcado desequilibrio a nivel de la cobertura informativa entre los siete periódicos estudiados.

La razón que justificaría dicho desequilibrio informativo se encuentra posiblemente en componentes ideológicos, incluso organizativos específicos económicos de cada uno de los periódicos estudiados. Así, observando los resultados obtenidos, podemos deducir que los dos diarios Le Matin y La Mañana del Sáhara y del Magreb, acaparan más de la mitad de las piezas comunicativas latinoamericanas. En concreto, el 55,34\% del corpus estudiado es generado por dichos medios. La preponderancia cuantitativa de este último 
diario se justificaría, sobre todo, por la cercanía lingüística que siente la cabecera estudiada con el mundo latinoamericano. Este hecho se refuerza tomando en consideración que es el único órgano periodístico de expresión en español en Marruecos. El segundo grupo está constituido por los cuatro diarios restantes: Al-Alam, L'Économiste, Anoual y, AlMassae, que acaparan unas cifras notoriamente inferiores.

Desde una perspectiva cronológica, una de las aproximaciones que se puede plantear es la idea de que la distribución de las unidades analizadas por años no resulta equilibrada; hay años en los que está cargada la producción informativa y, en cambio, otros años resultan pocos noticiosos. Respecto a este último aspecto, el presente estudio comprobó que los primeros años del estudio muestran una muy frágil presencia informativa, pero con el correr de los años, los periódicos marroquíes objeto de estudio recuperan un tímido espacio mediático del tema latinoamericano.

\subsection{Análisis de los temas encontrados en el corpus}

En este apartado se presentan los resultados vinculados con el análisis de los temas noticiosos sobre América Latina. Con el estudio de la temática se pretende conocer cuáles son los temas que la prensa marroquí comparte con sus lectores. Abajo se puede encontrar las categorías temáticas a la cuales los periódicos analizados dan mayor cobertura:

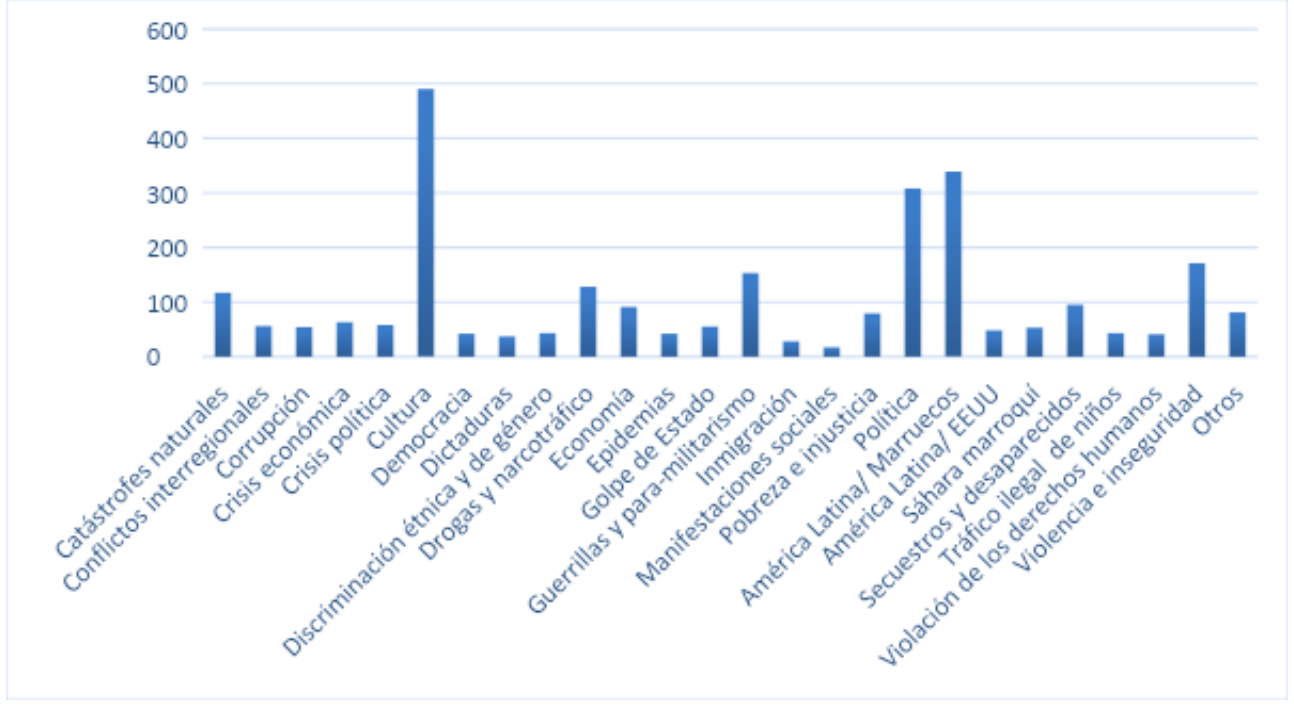

Gráfico No. 2: Los temas encontrados en el corpus (Fuente: elaboración propia) 
En vista del análisis de los contenidos de los resultados obtenidos, podemos apreciar la gran cantidad y variedad de aproximación temática de América Latina en el mapamundi periodístico marroquí. No obstante, un análisis en profundidad muestra que hay unos temas de los que se habla generosamente, y otros de los que apenas se dice nada. Tal como lo muestran los datos arriba expuestos, son cuatro los temas que concentran la mayor parte de las noticias de los diarios: a) cultura; b) relaciones de América Latina/Marruecos; c) política; d) violencia e inseguridad. Esta distribución muestra una opción informativa por privilegiar la cobertura de ciertos temas.

En efecto, el análisis permite observar que el mayor número de unidades de análisis se relaciona con el tema cultural. Este eje temático abarca un total de 490 artículos, o sea, el 17,80\% del corpus estudiado. La frecuencia refleja claramente el interés prioritario de la prensa marroquí de referencia por este tema. Se constata, en general, un mayor énfasis en la vertiente cultural; es la temática con mayor incidencia en la prensa de referencia, ya que da cabida a una amplia tipología informativa y es uno de los asuntos al que dedica más espacio.

Prosiguiendo esta comparación temática, las relaciones latinoamericano-marroquíes figuran en el segundo puesto en la escala de los resultados; este asunto encaja un total de 339 textos periodísticos. Esto parece sugerir que la prensa marroquí daba más prominencia a eventos relacionados con las relaciones diplomáticas recíprocas. Conviene matizar que esta área temática, además de que de por sí incluye muchos temas, ha podido obtener unos resultados más altos debido a la acción diplomática emprendida desde la llegada al poder del rey Mohamed VI en 1999. El momento álgido del interés informativo lo constituyó la gira histórica de Su Majestad el Rey Mohamed VI por América Latina. Aparte del tema de las relaciones de América Latina con Marruecos, el estudio examinó la presencia de otras unidades informativas que cubren la postura de algunos países latinoamericanos con respecto a la cuestión del Sáhara marroquí.

Los temas que hacen referencia a la política figuran en el tercer puesto en la escala de los resultados; este asunto da un resultado de un total de 308 artículos noticiosos. En relación con la naturaleza de estas publicaciones, hay que decir que todos los diarios estudiados coinciden en limitarse a dar una cobertura informativa a las dinámicas políticas relativas a las elecciones presidenciales latinoamericanas. Lo cual refleja una cierta preferencia por parte de la prensa marroquí estudiada por la agenda electoral latinoamericana.

Aparte de estos rasgos, hay que destacar de otros aspectos noticiosos que cambian el panorama respecto a los temas anteriores. En este mismo sentido, va a ser la violencia el tema estrella que ocupa un significativo espacio y frecuencia en el tratamiento temático de la prensa marroquí. Llama la atención que englobe tanta información que absorbe el 6,21\% de los artículos analizados. Luego, en su orden, aparece el tema de las guerrillas y los grupos paramilitares; es un asunto que aglutina el 5,55\% de los artículos publicados. Sobre la naturaleza de esas publicaciones, destacamos la idea de que las unidades informativas relativas a este eje temático arrojan luz sobre el Conflicto de Chiapas 
Tratamiento informativo de América Latina en la prensa marroquí

transcurrido entre el Gobierno de México y la guerrilla del Ejército Zapatista de Liberación Nacional (EZLN). También se dedica una importante referencia informativa al conflicto transcurrido entre el Gobierno de Colombia y las FARC. Le sigue el tema de las drogas y el narcotráfico. Las publicaciones informativas sobre este asunto abarcan el 4,65\% del corpus total. Cabe destacar que los periódicos marroquíes estudiados coinciden en ofrecer una buena parte de su cobertura informativa a algunas figuras asociadas con el narcotráfico, como es el ejemplo del mexicano Joaquín Guzmán "El Chapo”, y el colombiano Pablo Escobar. Otro tema que adquiere una notoriedad informativa en la prensa marroquí es el de las catástrofes naturales; este aspecto temático incluye un total de 184 artículos. Las piezas informativas analizadas ponen de relieve que la prensa marroquí cubrió extensamente las inundaciones y varios movimientos telúricos registrados en las tierras latinoamericanas. Por su parte, el análisis comprobó que, en el periodo analizado, los conflictos regionales comienzan a recibir una particular atención informativa en las páginas de los periódicos marroquíes seleccionados. En esta misma línea, hay que destacar que la guerra de Cenepa cobra un significativo peso informativo; desde entonces la sección Internacional de los periódicos marroquíes analizados se convierte en ventanal informativo de los conflictos acaecidos entre los dos países latinoamericanos.

No obstante, llama poderosamente la atención que la economía es el tema que menos cobertura ha recibido; apenas absorbe el 3,30\% del total de las publicaciones informativas. Lo cual hablaría de un notorio desinterés informativo por parte de la prensa marroquí por la cuestión de los negocios y la vertiente económica latinoamericana. En cuanto a la naturaleza de las piezas comunicativas publicadas sobre este asunto, el estudio efectuado muestra que los periódicos marroquíes analizados coinciden en dedicar un buen espacio informativo a la cobertura de algunas crisis económicas que se han dado en el subcontinente latinoamericano. En particular, la crisis económica de México (19941995) y la crisis económica de Argentina (1998-2002).

A partir de lo analizado podemos llegar a la conclusión de cómo el tratamiento temático gira en torno a aproximaciones culturales y políticas donde llama poderosamente la atención el tratamiento positivo que se da a las noticias sobre América Latina y los latinoamericanos. En base a estos hallazgos, es válido sugerir que, en los veinticinco años de estudio, los lectores de los periódicos marroquíes analizados tenían más posibilidades de leer artículos que describían América Latina como espacio rico en recursos artísticos y culturales. En los siguientes apartados se comparan los resultados obtenidos mediante las otras categorías y variables de análisis. 
Abdelhak Hiri

\subsection{Géneros periodísticos}

En esta categoría tratamos de mostrar de qué forma narran el acontecer latinoamericano los periódicos marroquíes escogidos en la muestra. El análisis de esta variable nos aporta luz sobre el grado de importancia del tema latinoamericano a los ojos del autor del artículo. También nos revela, entre otras, qué género predomina más en la información latinoamericana. El análisis de los géneros periodísticos nos arroja los siguientes valores:

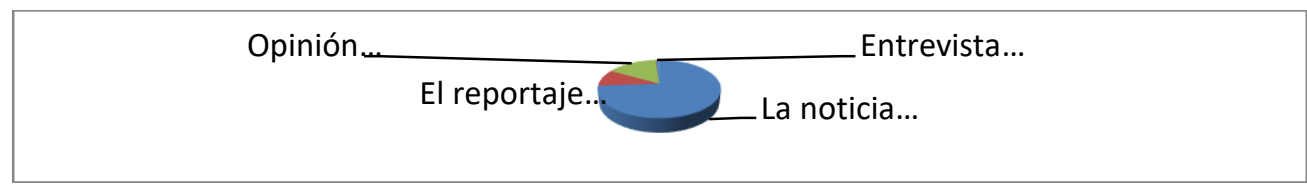

Gráfico No 3: Distribución porcentual de las piezas por género periodístico

(Fuente: elaboración propia)

Al estudiar la frecuencia de los géneros periodísticos de estos textos, se puede observar que la noticia es el género por excelencia, ya que alcanza una representación del $74 \%$ del corpus estudiado. Esta situación permite concluir que hubo una escasa aproximación interpretativa al tema latinoamericano, puesto que la noticia por sus mismas características (brevedad y concisión) ofrece una visión limitada y fragmentada de la realidad latinoamericana.

En cuanto al resto de los géneros publicados, se observó que los textos de opinión tienen una muy baja representatividad en los siete diarios analizados, con un valor de 432 piezas comunicativas. Se trata de un valor muy bajo; un total de $16 \%$ de textos de opinión frente a un $74 \%$ de textos informativos, con un valor de 2032 unidades. Lo cual evidencia que los diarios marroquíes estudiados tienen poco interés en hacer una cobertura periodística en profundidad y con investigación para abordar y publicar el acontecer latinoamericano. Las consecuencias que esta cobertura podría tener es ofrecer al lector marroquí una exposición informativa de baja profundidad analítica, para comprender y dimensionar el acontecer latinoamericano en sus dimensiones objetivas y explicativas.

\subsection{Fuentes informativas}

En el presente estudio abordamos otro aspecto igualmente clave para comprender la forma en que los periódicos marroquíes se aprovisionan de noticias informativas latinoamericanas. Con este estudio se permite determinar si la unidad informativa es elaborada por el propio periódico o reproducida de otros. El siguiente gráfico establece las principales fuentes identificadas: 
Tratamiento informativo de América Latina en la prensa marroquí

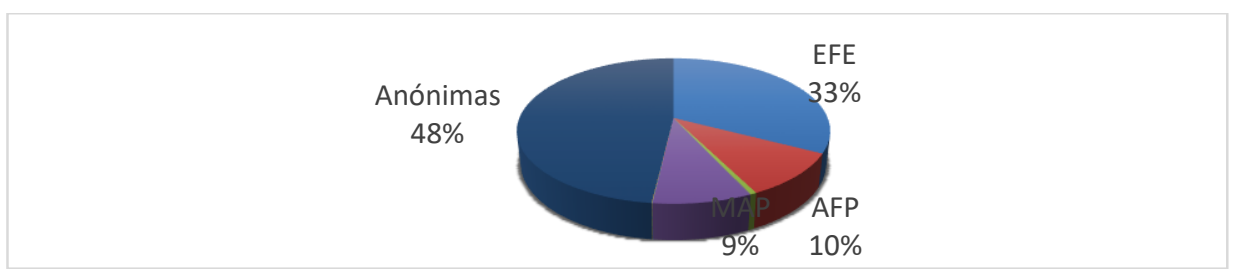

Gráfico No 4: Fuentes informativas (Fuente: elaboración propia)

Dos aspectos pueden ser destacados como puntos fuertes del material examinado: en primer lugar, se puede observar que el $48 \%$ de las unidades comunicativas carecen absolutamente de fuentes, mientras que las informaciones procedentes de las agencias de noticias representan el 55\% de la muestra. En segundo lugar, este estudio comprobó que al menos la mitad de las noticias internacionales examinadas procedían de dos agencias informativas internacionales: EFE y AFP.

Así, la agencia española EFE ratifica su liderazgo en número de fuentes. Es, de hecho, el primer motor de generación de noticias. Es preciso aclarar que su preponderancia se debe principalmente a su utilización abusiva por parte del periódico marroquí de expresión española, La Mañana del Sáhara y del Magreb. Este hallazgo implica que la prensa marroquí ofrece información latinoamericana mediada por la óptica española. Aparte de las referencias a los medios de España, la investigación ha experimentado que los medios analizados reservan un espacio privilegiado a los medios franceses como generadores de informaciones relativas a acontecimientos latinoamericanos. En este mismo sentido, es preciso destacar que el 10\% de las unidades informativas estudiadas surgen de la agencia AFP. De las 2752 piezas analizadas, un total de 255 textos periodísticos proceden de dicha agencia informativa.

Así pues, el estudio comprobó que una serie de agencias europeas controlan la mayor parte de las informaciones sobre el mundo latinoamericano que circula en el mapamundi periodístico marroquí. Este hecho se refuerza tomando en cuenta que fuentes españolas o francesas han podido generar más información latinoamericana que la propia agencia marroquí MAP. En esta misma línea, conviene destacar que este medio genera apenas el $12 \%$ de información latinoamericana: de las 2752 unidades registradas, un total de 223 están atribuidas a dicho órgano marroquí, lo que supone el 8,11\% del corpus analizado. Esta situación pone de relieve que las fuentes europeas monopolizan la información que la prensa marroquí emite sobre el mundo latinoamericano. Los resultados obtenidos sugieren que la prensa marroquí no supo transmitir a sus lectores una información personal y analítica como para extraer un conocimiento independiente y objetivo del acontecer latinoamericano.

La preponderancia de las fuentes de origen europeo sobre las nacionales, a nuestro juicio, es un elemento grave y preocupante, principalmente porque confirma que estamos ante la llamada en el periodismo "teoría de las dependencias" (Smith, 1984: 23) de las agencias de información. A este propósito, conviene citar la opinión de los autores Castel y Sendin: "Los hechos raramente son fuente directa de la noticia, porque entre la fuente 
primaria y quien tiene que llevar a cabo la operación de seleccionar y elaborar" (2009: 154). Atendiendo a esta reflexión, podemos deducir que la dependencia de las agencias tiene graves repercusiones. En nuestro caso, el abuso de la prensa marroquí de las agencias y fuentes extranjeras podría cuestionar la misma identidad de dichos periódicos marroquíes estudiados. Osorio Martínez-Fresneda se pronuncia sobre esta cuestión en estos términos:

El periodista debe siempre confirmar y contrastar la información facilitada por las agencias de información como cualquier información que no es propia debe ser comprobada (2004: 272).

\subsection{Análisis comparativo de la distribución de las unidades informativas según el área geográfica}

En este punto tratamos de identificar los países latinoamericanos que suscitan mayor interés mediático para la prensa marroquí. La comparativa con este grupo de países resulta interesante, ya que nos ofrecerá la percepción de los diferentes países en el mapamundi periodístico marroquí. En el siguiente gráfico encontramos la representación porcentual que refleja la aparición de cada país en el total de piezas analizada:

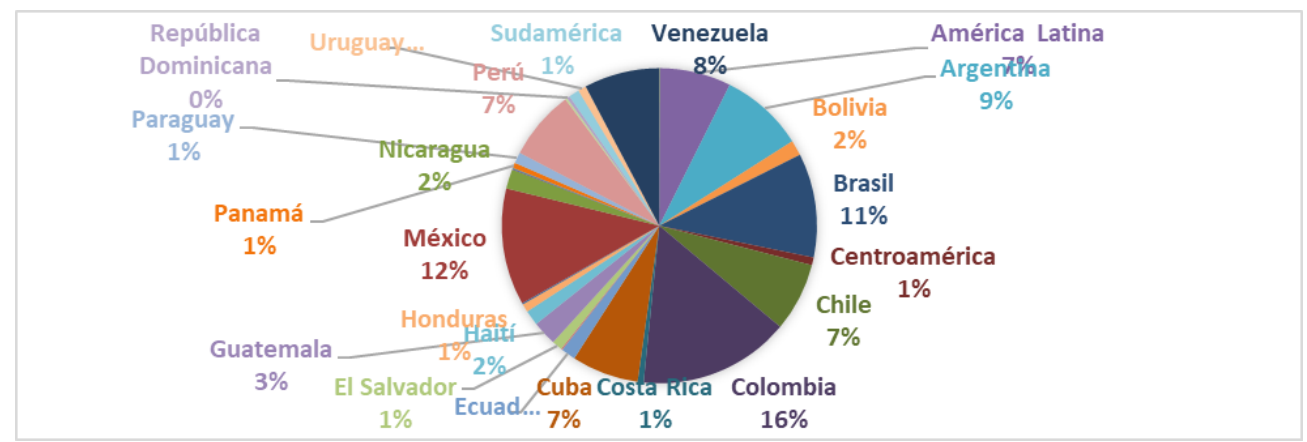

Gráfico No.5: Distribución porcentual de las noticias por países (Fuente: elaboración propia)

Los resultados obtenidos permiten experimentar que no se puede concluir que nos encontremos con un sentido de integración informativa del subcontinente latinoamericano. El tratamiento informativo de América Latina varía por países. Efectivamente, se desprende una cobertura muy discriminada y desigual; hay países latinoamericanos de los que se habla generosamente, y otros de los que apenas se habla. En otros términos, esta investigación ha demostrado la sobre-aparición de zonas específicas, tanto desde la perspectiva cuantitativa como desde el espacio asignado, mientras hay otras que pueden considerarse como desiertos mediáticos por encontrar una cobertura informativa cero sobre ellos. 
En efecto, si comenzamos por la comparativa en el aparato de los países protagonistas, podemos observar los países de mayor dimensión, en orden decreciente: Colombia, México, el Perú, Argentina encabezan el ranking de volumen de noticias analizadas por la prensa marroquí. Chile cierra el ranking de estos cinco países. Dichos países se presentan como uno los objetivos prioritarios de la prensa marroquí. En el extremo opuesto, hay varios países que denotan una muy frágil referencialidad informativa. Llama poderosamente la atención que hay países que casi ni se mencionan, como ocurre con Costa Rica, Panamá, República Dominicana, Puerto Rico.

Continuando con las observaciones, la investigación ha podido comprobar que existe una correlación entre la variable del espacio dedicado a cada país y la temática en la que se enmarca. Esto conlleva que determinados países estén asociados a determinadas temáticas, de forma que podría hablarse de países maltratados y países prestigiosos mediáticamente. Entre los primeros cabe destacar Colombia, Venezuela, el Perú, Guatemala y Haití, que, por distintas razones, se asocian a temas como los conflictos armados, las drogas y los desastres naturales, y sus informaciones suelen mantener un carácter negativo marcado por los estereotipos. En países como Uruguay, Nicaragua, Bolivia y Ecuador, prevalecieron las informaciones políticas. Entre los países mimados por la prensa marroquí se encuentran Argentina (vinculado con temas como la cultura, la literatura y las buenas relaciones diplomáticas y económicas), Brasil (cuyas informaciones se asocian con los asuntos culturales y económicos), México (con una cobertura asociada a las relaciones internacionales, la cultura y la inmigración) y Costa Rica (aunque con muy poca referencialidad, este país es retratado como una de las mejores democracias de América Latina).

En síntesis, la prensa marroquí da mayor visibilidad informativa a aquellos países latinoamericanos con los que Marruecos establece un mayor acercamiento a nivel de sus relaciones exteriores. Esta situación permite constatar que la agenda de información latinoamericana responde a intereses gubernamentales.

\section{Conclusión}

Como fruto del presente trabajo de investigación, se han obtenido resultados interesantes y reveladores, que pueden convertirse en una base de datos para continuar profundizando en la representación de América Latina en el discurso mediático marroquí. Cabe destacar que los contenidos que se presentan en los periódicos analizados han experimentado que, pese a la limitación de la falta de homogeneidad temporal y el posicionamiento editorial, los medios analizados tienen numerosos rasgos en común que hacen posible que se pueda establecer una relación comparativa entre ellos. De esta manera, pueden ser destacados los siguientes aspectos:

La primera gran conclusión que se extrae de esta investigación, aunque se manifestaron ciertas diferencias en la cobertura informativa que ofrecen los siete diarios de América Latina, todos coincidían en ofrecer a sus lectores una información deficiente 
Abdelhak Hiri

de América Latina. A la luz de esta primera conclusión, los lectores marroquíes permanecen aislados de lo que sucede en el mundo latinoamericano, mostrando una gran ignorancia y desconocimiento del subcontinente latinoamericano.

Un segundo hallazgo relevante que se hace necesario destacar es que los periódicos marroquíes estudiados realizan un uso abusivo de las agencias internacionales. La prensa marroquí no llega a producir noticias originadas en el suelo latinoamericano. De ahí llama poderosamente la atención que la visibilidad informativa de América Latina en la prensa marroquí es construida principalmente por terceros.

Del estudio dedicado a los géneros periodísticos se desprende que la noticia conserva plenamente su papel preponderante en los siete diarios analizados. Esta observación es generalizable a los siete diarios analizados. Una abrumadora mayoría se presenta bajo forma de noticias breves. Las consecuencias que esta cobertura podría tener es ofrecer al lector marroquí una exposición informativa de baja profundidad analítica, para comprender y dimensionar el acontecer latinoamericano en sus dimensiones objetivas y explicativas.

Del estudio dedicado a la distribución de las unidades informativas por área geográfica, debemos indicar que no se puede concluir que nos encontremos con un sentido de integración informativa del subcontinente latinoamericano. El tratamiento informativo de América Latina varía por países.

Por lo que se refiere al estilo temático, el análisis comprobó una representación desequilibrada. La distribución de cobertura e importancia que cada diario le da a los diversos temas es diferente, hay unos temas de los que se habla generosamente, y otros de los que apenas se dice algo. Esto se refleja en que algunos temas están más cubiertos que otros o incluso que algunos tienen cobertura cero o cobertura pasajera.

En vista de todo lo anterior, creemos necesario que la prensa marroquí, para estar a la altura de las grandes dinámicas sociopolíticas latinoamericanas, deba incorporar periodistas que sean especialistas en esta área, ampliar la inversión en los recursos económicos para el envío de periodistas encargados de cubrir los sucesos, contar con los propios periodistas latinoamericanos, crear bloques donde se analicen temas o hechos ocurridos en el subcontinente latinoamericano. También, sería necesario no depender de lo que están comentando las grandes agencias informativas internacionales.

\section{Referencias bibliográficas}

Bardin, Laurence (1991). Análisis de contenido. Madrid: Akal.

Castel, Antoni - Sendín, José Carlos (2009). Imaginar África: los estereotipos occidentales sobre Africa y los africanos. Madrid: Los libros De Catarata/ Casa África.

Mccombs, Maxwell (1996). Influencia de las noticias sobre nuestras imágenes del mundo. En: Bryant, Jennings - Zillmann, Dolf (1996). Los efectos de los medios de comunicación: investigaciones y teorías. Barcelona: Paidós. 
Tratamiento informativo de América Latina en la prensa marroquí

Martínez-Fresneda, Osorio (2004). Las fuentes del periodismo informativo. En: Cantavella, José (coord.). Redacción para periodistas: informar e interpretar. Barcelona: Ariel.

Rodríguez Díaz, Raquel (2004). Teoría de la agenda setting: Aplicación a la enseñanza universitaria. Alicante: Observatorio Europeo de Tendencias Sociales.

Saldívar, Alejandro (2014). La hidra y la alfombra roja: imágenes de la guerra contra el narcotráfico. Saarbrücken: Redactum.

Smith, Anthony (1984). La geopolitica de la información. México: Fondo de Cultura Económica de México.

Ramírez, Ana S. (2005). El texto de opinión de la prensa escrita. Las Palmas de Gran Canarias: Universidad Las Palmas de Gran Canarias. 